\title{
Use of structural synthesis of mechanisms for dynamic simulation in Autodesk Inventor
}

\section{MAREK BORYGA \\ PAWEL KOŁODZIEJ *}

\author{
Dr hab. inż. Marek Boryga, marek.boryga@up.lublin.pl, https://orcid.org/0000-0002-5991-7871 - Uniwersytet Przyrodniczy, Lublin, \\ Polska \\ Dr inż. Paweł Kołodziej, pawel.kolodziej@up.lublin.pl, https://orcid.org/0000-0003-0479-1770 - Uniwersytet Przyrodniczy, Lublin, \\ Polska
}

The use of structural synthesis of mechanisms for dynamic simulation in Autodesk Inventor is presented. The stages of preparation for dynamic simulation (in particular the creation of connections between links) and the method of an intermediate chain enabling the creation of complete sets of structural solutions are presented. The procedure is illustrated by two examples.

KEYWORDS: structural synthesis, dynamic simulation, mobility of the mechanism, intermediate chain method

\section{Introduction}

The initial stage of designing the mechanisms constituting assemblies and sub-assemblies of machines is the proper selection of their structural diagrams. In many cases, structural modification of existing kinematic systems or a solution based on a random idea can lead to the use of irrational solutions. The designer should have a full set of theoretically possible structural schemes, because this determines the selection of the most favorable kinematic system [3].

The publication [1] presents the structural synthesis and classification of parallel manipulators. Methods for creating structural solutions with one or more platforms were presented, and they were classified by type of platforms and connections. The work [2] presents the method of structural synthesis of flat or spatial parallel mechanisms. It enables the creation of structural schemes, and the end result is a complete set of possible solutions of the spatial parallel mechanism for the required mobility. The work [3] provides an overview of issues in the field of the structure of mechanical systems. The authors discussed the methods of creating sets of possible solutions for kinematic systems and presented a catalog of selected types of mechanisms, sorted by type of active and passive cell. The work [4] presents the methodology for designing parallel manipulators. Structural synthesis of kinematic chains with six degrees of freedom was performed, creating a generic chain that can be reconfigured for additional solutions.

The purpose of this paper is to demonstrate how to use the hash chain method in the Dynamic Simulation module of Autodesk Inventor.

\section{Autodesk Inventor dynamic simulation module}

The first stage of dynamic simulation in Autodesk Inventor is to prepare the 3D model for analysis. It consists in separating the elements of the mechanism into fixed and mobile links and creating bonded groups, i.e. connections of elements that move together. The next step is to define the types of connections between the links of the analyzed mechanism.

In the Autodesk Inventor dynamic simulation module, the constraints are divided into: standard, rolling, sliding, 2D contact and force. Most standard connections have equivalents in the classification of kinematic pairs and can be created using automatic conversion of assembly bonds. Other types of connections are only created manually.

Classification of kinematic pairs is presented in tab. I [6], and in tab. II [7] - standard connections that occur in the Dynamic Simulation module. 
TABLE I. Classification of kinematic pairs [6]

\begin{tabular}{|c|r|r|r|}
\hline Class & Form 1 & Form 2 & Form 3 \\
\hline I & & & \\
\hline II & \\
\hline III & & \\
\hline IV & & & \\
\hline $\mathrm{V}$ & & & \\
\hline
\end{tabular}

TABLE II. Standard connections of the Dynamic Simulation module [7]

\begin{tabular}{|c|c|c|c|}
\hline Connection name & Connection symbol & $\begin{array}{l}\text { Equivalent in } \\
\text { table I }\end{array}$ & Description \\
\hline spatial & & $\begin{array}{l}\text { it is not a kinemat- } \\
\text { ic steam }\end{array}$ & $\begin{array}{l}\text { rotation around axis } y \text { and } z \\
\text { offset along the axis } x, y \text { and } z\end{array}$ \\
\hline point-plane & & $\begin{array}{l}\text { class I } \\
\text { form } 1\end{array}$ & $\begin{array}{l}\text { rotation around axis } y \text { and } z \\
\text { offset along the axis } x \text { and } z\end{array}$ \\
\hline point-line & & $\begin{array}{l}\text { class II } \\
\text { form } 1\end{array}$ & $\begin{array}{c}\text { rotation around axis } \mathrm{x}, y \text { and } z \\
\text { offset aroundaxisz }\end{array}$ \\
\hline line-plane & & $\begin{array}{l}\text { class II } \\
\text { form } 2\end{array}$ & $\begin{array}{l}\text { rotation around axis } y \text { and } z \\
\text { offset along the axis } x \text { and } z\end{array}$ \\
\hline spherical & & $\begin{array}{l}\text { class III } \\
\text { form } 1\end{array}$ & offset along the axis $x, y$ and $z$ \\
\hline flat & & $\begin{array}{l}\text { class III } \\
\text { form } 3\end{array}$ & $\begin{array}{c}\text { rotation around axis } y \\
\text { offset along the axis } x \text { and } z\end{array}$ \\
\hline cylindrical & & $\begin{array}{l}\text { class IV } \\
\text { form } 2\end{array}$ & $\begin{array}{c}\text { rotation around axis } z \\
\text { offset along the axis } z\end{array}$ \\
\hline rotary & & $\begin{array}{l}\text { class } V \\
\text { form } 1\end{array}$ & rotationaroundaxisz \\
\hline prismatic & & $\begin{array}{l}\text { class } V \\
\text { form } 2\end{array}$ & offset along the axis $z$ \\
\hline weld & & $\begin{array}{l}\text { it is not a kinemat- } \\
\text { ic steam }\end{array}$ & no shift and rotation \\
\hline
\end{tabular}

\section{Mechanism synthesis - intermediary chain method}

In each mechanism (fig. 1), the base 0 , active part C, passive part B and intermediate link chain $U$ [3] can be distinguished. Mobility $W$ of the mechanism can be calculated from:

$$
W=W_{c}+W_{u}+W_{B}
$$

where: $W C$ - active cell mobility, $W U$ - intermediate chain mobility, $W B$ - passive member mobility.

When the number of degrees of freedom for $W, W C$ and $W B$ is known, the mobility of the intermediate chain can be calculated:

$$
W_{u}=W-W_{C}-W_{B}
$$


The mobility $W$ of the flat kinematic chain is:

$$
W=3 \cdot n-2 \cdot p_{5}-p_{4}
$$

where: $n$ - number of mobile cells, $p 5$ - number of class V kinematic pairs, $p 4$ - number of class IV kinematic pairs.

In turn, the mobility of the spatial mechanism is determined by the formula:

$$
W=6 \cdot n-\sum_{i=1}^{5} i \cdot p_{i}
$$

where: $i$ - kinematic pair class, $p i$ - number of kinematic pairs of class $i$.

Using the relationships (3) or (4) on the mobility of the mechanism, for the mobility of the intermediate chain, determined from equation (2), a formula is obtained that for flat mechanisms takes the form (5), and for spatial mechanisms - the form (6):

$$
\begin{gathered}
3 \cdot n-W_{u}=2 \cdot p_{5}+p_{4} \\
6 \cdot n-W_{u}=\sum_{i=1}^{5} i \cdot p_{i}
\end{gathered}
$$

The numbers $n$ and $p i$ are natural numbers, therefore equations (5) and (6) allow the determination of a certain number of variants of structural solutions of the intermediate chain $U$ [3].

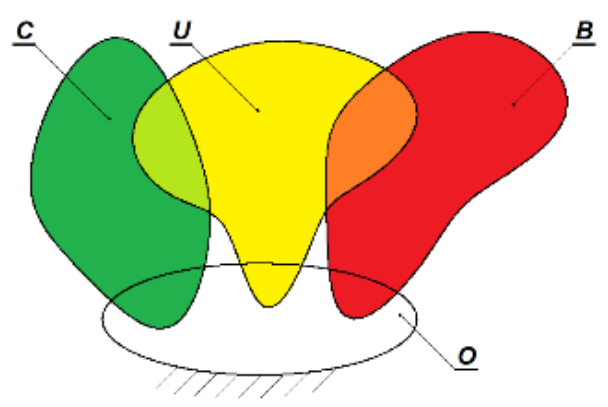

Fig. 1. Concept of building a mechanism with an intermediate chain ( 0 - base, $\mathrm{C}$ - active part, $\mathrm{B}$ - passive part, $U$ - intermediate link chain) [3]

\section{Flat mechanism - slide clamp}

Fig. 2 shows a 3D model of a slide clamp.

In the dynamic simulation module, one prismatic connection (base - slide) and three rotary connections (base-lever, lever-connector, connector-slide) were created. The mobility calculated from the formula (3) is $W$ $=1$.

Fig. 3 presents a 3D model of the intermediate chain used in the original solution.

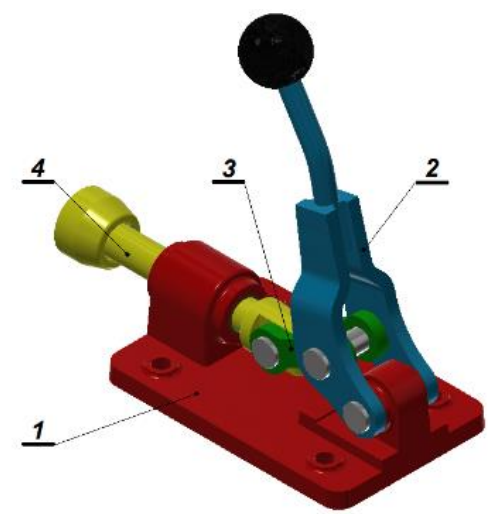

Fig. 2. 3D model of a slide clamp (1 - base, 2 - lever, 3 - connector, 4 - slide) 


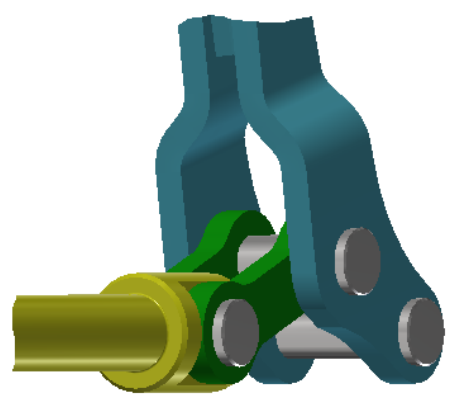

Fig. 3. 3D model of the intermediate chain of the slide clamp for the primary solution

After inserting the last connection, a message about excessive binding of the mechanism (by three degrees of freedom) appears. This is due to the fact that in the dynamic simulation module all mechanisms are treated as spatial. When the actual mobility of the mechanism $W$ is known, the number of passive constraints $r$ can be calculated:

$$
r=W^{\prime}-W
$$

In the analyzed mechanism, the mobility calculated from the formula (4) is $W=-2$, the real mobility is $W^{\prime}=$ 1 , and the number of passive constraints is $r=3$.

In the dynamic simulation module, the number of passive constraints was called the degree of reduction, while the actual mobility - the degree of movement.

The program constantly checks the status of connections and informs the user about redundant connections. After clicking the Mechanism Status icon and expanding the window, one can see a replacement of the leverconnector rotational pair with a point-line pair (fig. 4). This exchange eliminates passive bonds. The mobility calculated from formula (4) is then $W=1(n=3, p 5=3, p 2=1, p 4=p 3=p 1=0)$, and the number of passive constraints $r=0$.

Using the intermediate chain method, in equation (2), substitute $W=1, W C=1$ and $W B=1$. The calculated required mobility of the intermediate chain is $W U=-1$. After introducing the limit $n=1$ and $p 1=0$ and inserting into equation (6) $W U=-1$, the solutions given in tab. III.

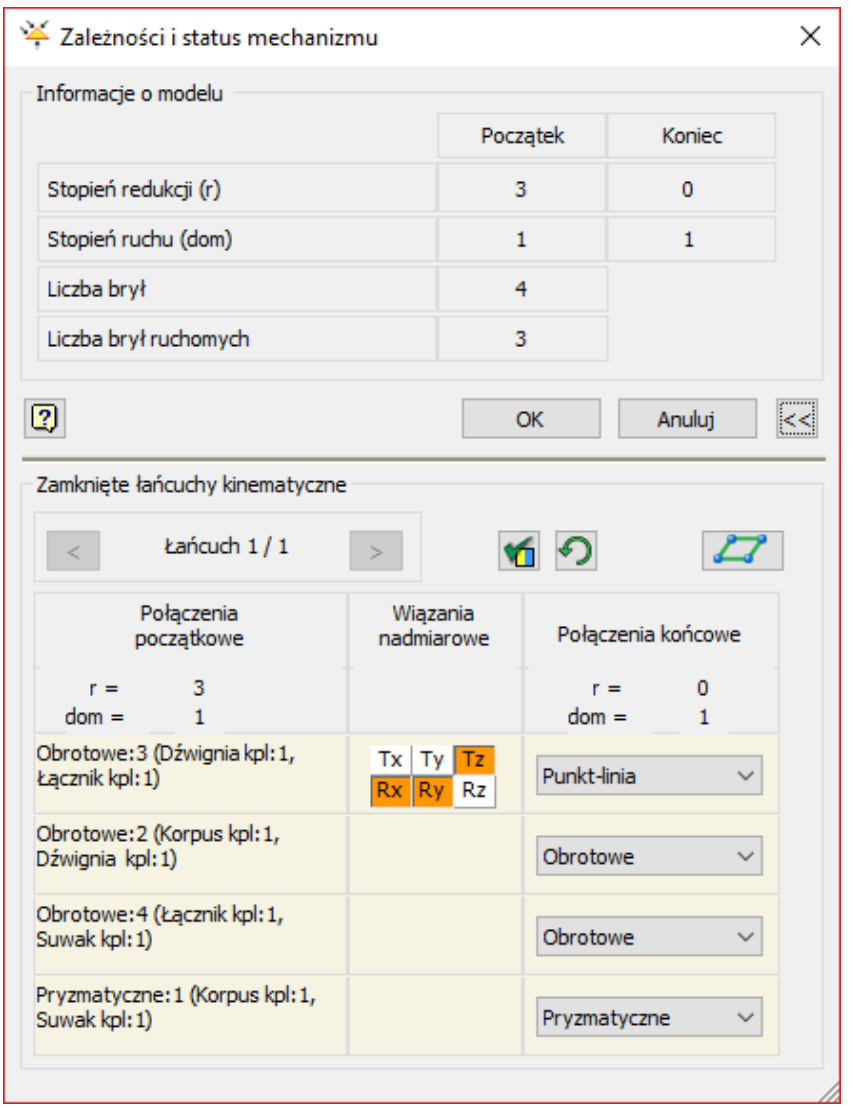

Fig. 4. Dependencies window and mechanism status for the original solution 
TABLE III. Variants of the solution of the intermediate chain of the slide clamp

\begin{tabular}{|c|c|c|c|c|c|}
\hline No.. & $n$ & $p_{5}$ & $p_{4}$ & $p_{3}$ & $p_{2}$ \\
\hline 1 & \multirow{4}{*}{1} & 1 & 0 & 0 & 1 \\
\hline 2 & 0 & 1 & 1 & 0 \\
\hline $3 n n n y y$ & & 0 & 0 & 1 & 2 \\
\hline
\end{tabular}

The lever-connector pair rotary pair suggested by the program for point-line pair is in the tab. III marked with number 1 . The solution marked with number 2 was chosen as rational - its 3D model is shown in fig. 5 .

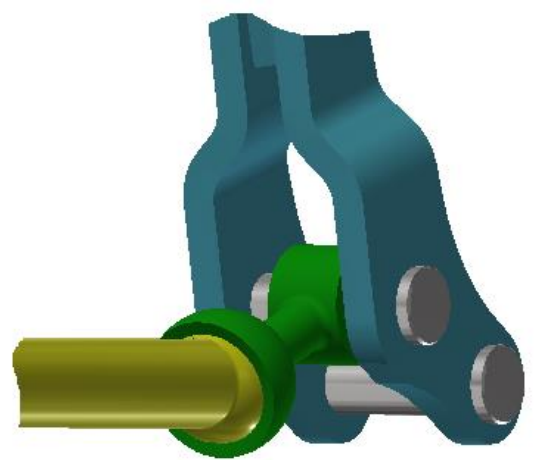

Fig. 5. 3D model of the intermediate chain of the slide clamp for the selected solution

After inserting a rotary connection (base-lever), cylindrical (lever-connector), spherical (connector-slider) and prismatic (base-slider) and after clicking the Mechanism status icon in the dynamic simulation module, the window shown in fig. 6 appears.

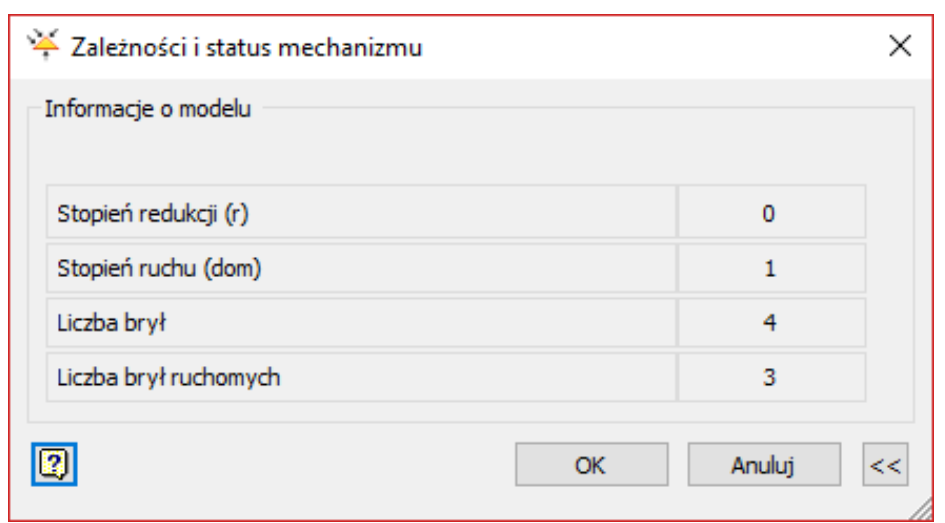

Fig. 6. The Dependencies window and the status of the mechanism for the clamp with the intermediate chain shown in fig. 5

The proposed solution is a mechanism without passive ties. Such mechanisms are characterized by [6]:

- insensitivity to execution errors,

- easy assembly and repair,

- partial or complete elimination of break-in.

\section{Spatial mechanism - parallel manipulator}

The intermediate chain method can also be used to design a parallel manipulator. Then in equation (2) $W=$ $3, W C=0$ and $W B=6$. Assuming that the intermediate chain will consist of three identical chains $(W U=3 W t)$, the mobility of a single chain can be calculated:

$$
W_{t}=\frac{W-W_{C}-W_{B}}{3}=-1
$$

After using the relationship (6) and introducing restrictions $n \leq 3, p 1=0, p 2=0$, eight possible solutions of the intermediate chain are obtained, presented in tab. IV. 
Fig. 7 shows a selected 3D model of a parallel manipulator. It is based on a stationary plate 1 with bearing elements and motors driving the active links 2 . Cardan joints 3 connect the members 2 with the passive links 4 and the members 4 with the working platform 5 .

The solution presented in fig. 7 (when the cardan joint is treated as a class IV kinematic chain pair [5]) in tab. IV is marked with number 6 .

TABLE IV. Variants of resolving the intermediate manipulator intermediate chain

\begin{tabular}{|c|c|c|c|c|}
\hline Lp. & $n$ & $p_{5}$ & $\mathrm{p}_{4}$ & $\mathrm{p}_{3}$ \\
\hline 1 & \multirow{4}{*}{3} & 3 & 1 & 0 \\
\hline 2 & & 2 & 0 & 3 \\
\hline 3 & & 1 & 2 & 2 \\
\hline 4 & & 0 & 4 & 1 \\
\hline 5 & \multirow{3}{*}{2} & 2 & 0 & 1 \\
\hline 6 & & 1 & 2 & 0 \\
\hline 7 & & 0 & 1 & 3 \\
\hline 8 & 1 & 0 & 1 & 1 \\
\hline
\end{tabular}

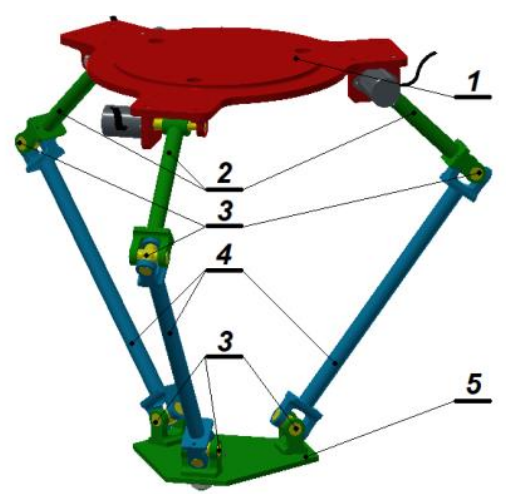

Fig. 7. 3D model of the parallel manipulator ( 1 - fixed plate being the base of the manipulator, 2 - active links, 3 - cardan joints, 4 - passive links, 5 - working platform)

\section{Summary}

The application of the intermediate chain method allows the selection of rational structural solutions of kinematic chains from all possible configurations of kinematic pairs, forming the working mechanisms of machines and devices. Combination of kinematic pairs classification and mechanism mobility determination with elements of the Autodesk Inventor Dynamic Simulation module explains and specifies the use of proposed variants of structural solutions. In addition, it increases the creation possibilities and facilitates the correct selection of kinematic pairs of specific classes - for both flat and spatial mechanisms. In the process of designing elements, assemblies of machines and mechanisms, it is an effective tool supporting the work of the designer.

\section{REFERENCES}

[1] Alizade R., Bayram C. "Structural synthesis of parallel manipulators". Mechanism and Machine Theory. 39, 8 (2004): 857-870.

[2] Bałchanowski J. "General method of structural synthesis of parallel mechanisms". Archives of Civil and Mechanical Engineering. 16, 3 (2016): 256-268.

[3] Gronowicz A., Miller S. „Mechanizmy. Metody tworzenia zbiorów rozwiq̨zań alternatywnych. Katalog schematów strukturalnych i kinematycznych". Wrocław: Oficyna Wydawnicza Politechniki Wrocławskiej, 1997.

[4] Ibarreche J.I., Hernández A, Petuya V., Urizar M., Macho E. "Multioperation capacity of parallel manipulators basing on generic kinematic chain approach". Mechanism and Machine Theory. 116, 8 (2017): 234-870.

[5] Miller S. „Układy kinematyczne. Podstawy projektowania”. Warszawa: Wydawnictwa Naukowo-Techniczne, 1988.

[6] Olędzki A. „Podstawy teorii maszyn i mechanizmów”. Warszawa: Wydawnictwa Naukowo-Techniczne, 1987.

[7] Stasiak F. „Zbiór ćwiczeń AutodeskInventor 2018. Kurs Professional”. ExpertBooks, 2018 